attending to my business I discovered that was simply because I had not fulfilled the conditions of success.

I have no doubt but that Mr. Hilliard's instrument is an admirable one and $I$ regret that I must say--judging from his lucid description and the picture accompanying it-I prefer something I can easily hold in my hand to an inhaler fixed on a board which has to be fixed under the mattress; something I can hang up near me to an instrument that needs a table for its accommodation; something that by its "click-click" tells me the respirations are all right and at a glance that oxygen as well as chloroform is reaching the lurgs. For, as he truly says, "chloroform can never be quite safe." Is anything quite safe ever in excess?

I am, Sirs, yours faithfully,

July 31st, 1905

DAVID ANDERSON-BerRY, M.D., F.R.S. EdIN.

\section{THE USE OF PHENYLHYDRAZIN IN THE EXAMINATION OF URINE.}

To the Editors of THE LANCET.

SIRs, - I regret having overlooked the point to which $\mathrm{Dr}$. P. J. Cammidge refers in THE LANCET of July 29th, p. 316. In his article in your issue of July 1st it certainly seemed to me that he was adrocating the rapid method of using this test. I am aware that operating with aqueous solutions is not quite the same as is the case with a urinary solution, but even in this latter case $I$ find that if 0.3 gramme of maltose or lactose be dissolved in 100 cubic centimetres of normal urine and the phenylhydrazin test be then applied, an appreciable deposit of osazone crystals results if the water bath be used, whilst boiling over the free tlame for five minutes elicits no response at all. With regard to dextrose $I$ have repeatedly found that if the urine contained but a very small quantity a positive reaction could almost invariably be relied on after 30 minutes of the water bath; but this was by no means the case with the rapid method. Further, I have had the same experience when nsing Dr. Cammidge's own test for pancreatic urine.

I am, Sirs, yours faithfully,

Langley-green, Birmingham, July 31st, 1905.

$$
\text { L. C. S. Broughton. }
$$

\section{TEMPORARY FIXATION OF AN IMPER- FECTLY DESCENDED TESTIS TO THE THIGH. \\ To the Editors of THE LANCET.}

SiRs, - I have read with much interest Mr. O. B. Keetley's further account of his procedure as given in THE LANCET of July 29th, p. 279 . I have no doubt whatever that an imperfectly descended testis has, in the great majority of cases, some value. If it lie within the abdominal cavity I believe it has a greater value than if it has been arrested in the inguinal canal or high in the scrotum. Seeing that one has so constantly to operate for the hernia, potential or actual, which is nearly always present, what should be done with the retained testis is a matter of moment. If it is of value it should not be removed. If it can be brought down into, and kept down in, the scrotum this has undoubted advantages. But there are very few cases in which this permanent position is attained Mr. Keetley does not state in how many it occurred in his 25 cases, but merely "the testis generally remains permanently in the scrotum but near its root." I am not sure what is meant by the "root of the scrotum," but I am sure that a testis placed at the level of the root of the penis is little if at all better off than one in the inguinal canal. Again, Mr. Keetley asks the question, "Do these testes grow when brought down in the scrotum?" and he answers, "Undoubtedly some of them do but not to the size of normal testes." Again, he does not give numbers, and accurate statistics are what is needed on this interesting question. I, personally, have never seen a testis increase in size after being artificially brought one inch or so lower down-that is, into the upper part of the scrotum. If any have done so $I$ do not believe that their forcible displacement has had anything to do with their subsequent enlargement. On the other hand, I have seen many testes both in my own practice and in that of other surgeons diminish in size after being pulled down. Further, I am at variance with Mr.
Keetley when he says that a testis just below the superficial abdominal ring-that is, just below the inguinal canal-is in a comfortable position. My experience is that testes which have reached this position naturally, but have been arrested there, are very apt to be drawn up at times against and through the pillars of the opening, whereby much pain is caused, and that even when no actual hernia exists. To fix a testis artificially here is to leave it subjected to these pulls during the movements of the abdominal muscles and to leave the patient liable to intermittent suffering. Mr. Keetley has been fortunate not to come across such a condition. I have and have had several times to remove the testis for it. But if the testis is of value and cannot be satisfactorily brought down and should not be removed there is still another procedure which may be adopted. This is to return it, after it has been freed if necessary, within the abdominal cavity. I have never regretted doing this. The testis is placed, like the ovary, in a comfortable position, the inguinal canal can be completely closed, and there is only a mythical increased tendency for it to become the site of malignancy. I find more and more surgeons are adopting this simple method and with the most gratifying results. I am, Sirs, yours faithfully,

Harley-street, W., July 29th, $1905 . \quad$ W. MCADAM ECCLES,

\section{THE TREATMENT OF FRACTURED RIBS.}

\section{To the Editors of THE LANCET.}

SrRs,-The treatment of fractured ribs by strapping is probably less satisfactory to the patient than to the surgeon. From personal experience it seems so to me. When in South Africa I had three ribs and a shoulder-blade fractured I was well strapped in routine fashion but was relieved for a short time only, the strapping only too soon becoming loose. Pain prohibited me from lying in bed, doubtless owing to the fractured shoulder-blade, at that time not diagnosed. It then occurred to me that fixation by something resembling a stays would be an improvement upon the old method. A simple binder on these lines made of stiff jean I had made, fitted to lace up at the back and tie in front. Shoulder bands (of tape) also to tie at convenience kept the binder in position. The objection naturally raised to this treatment would be that it was a restraint not only on the injured but also on the uninjured side of the chest and calculated to interfere with the breathing. As a subject of spasmodic asthma from early childhood I can only say that it does not appear to be so. The relief obtained from the home-manufactured stays was enormous and I had no dyspncea. As far as the ribs were concerned the treatment was entirely satisfactory.-I am, Sirs, yours faithfully,

Frank Elvy, M.R.C.S. Eng., L.R.C.P. Lond. Broadwindsor, July 31st, 1905.

\section{FREE MEALS, CLOTHES, AND MEDICAL TREATMENT FOR THE SCHOOL CHILDREN OF BRUSSELS.}

\section{(From OUR SPECIAL SANITART COMMissioner.)}

Brussels, July, 1905

THovgr the agglomeration of independent boronghs which is called Brussels is very small as compared to the metropolis of London, the city of Brussels is very much larger than the City of London. The agglomeration Bruxelloise may count some 600,000 inhabitants, a third of whom live in the city of Brussels itself. It is not a third or even a thirtieth part of the inhabitants of the metropolis that live in the City of London. In any case, whatever the historic city of Brussels has done is a matter of importance throughout Belgium and often serves as an example for the whole nation. In view of the physical degeneration of certain sections of the population not only in England but in all industrial countries, and of the fact that on all sides there is a very general conviction that better care must be taken of the children in the primary schools, I have made some inquiries as to what has been done here. Unfortunately for many years Belginm has been distracted by a fierce conflict for and against 